"Enhancement of in vivo Antitumor Activity of a Novel Antimitotic 1-Phenylpropenone Derivative, AM-132, by Tumor Necrosis Factor- $\alpha$ or Interleukin-6" by Tatsumi et al. [Jpn. J. Cancer Res., 92: 768-777, 2001]: Errors occurred in chemical structures in Fig. 1. The corrected figure is described below. None of the errors alters the interpretation of the data or the authors' conclusions. The authors regret the errors.

\title{
Yasuaki Tatsumi ${ }^{1,4}$ \\ Hitoshi Arioka ${ }^{1}$ \\ Shun-ichi Ikeda $^{3}$ \\ Hisao Fukumoto ${ }^{1}$ \\ Ken-ichi Miyamoto ${ }^{4}$ \\ Kazuya Fukuoka ${ }^{1}$ \\ Yuichiro Ohe ${ }^{2}$ \\ Nagahiro Saijo ${ }^{2}$ \\ Kazuto Nishio
}

${ }^{1}$ National Cancer Center Research Institute, ${ }^{2}$ National Cancer Center Hospital, ${ }^{3}$ Kyowa Hakko Kogyo Co., Ltd. and ${ }^{4}$ Kanazawa University<smiles>COc1cc(C(=O)/C=C/c2c[nH]c3ccccc23)cc(OC)c1OC</smiles>

TK5048<smiles>COc1cc(C(=O)/C(C)=C/c2c[nH]c3cc(C)ccc23)cc(OC)c1OC</smiles>

AM-97<smiles>COc1cc(C(=O)/C(=C/c2c[nH]c3ccccc23)SCC(O)CO)cc(OC)c1OC</smiles>

AM-132<smiles>COc1cc(C(=O)/C(=C/c2c[nH]c3cc(C)ccc23)SCC(O)CO)cc(OC)c1OC</smiles>

AM-138

Fig. 1. Chemical structures of TK5048 and its derivatives, AM-97, AM-132 and AM-138. 